\title{
Factors influence household solid waste recycling behaviour in Thailand: an integrated perspective
}

\author{
A. Ittiravivongs \\ Graduate School of Business and Commerce, Keio University, Japan
}

\begin{abstract}
The achievement of recycling programs depends essentially on the active and sustained involvement of people. In order to investigate factors that influence households' decision to participate in recycling programs, this research applied directed interviews, observations, and questionnaire surveys to study recycling behavior of 381 randomly selected individuals in Bangkok. The study employed the theory of planed behavior as the main framework and injected sociodemographic, economic, and situational factors into the model to examine how these factors integrate to either stimulate or restrain recycling involvement of people. The results of the estimated logistic regression models suggested that the adequacy of information regarding recycling and resident period in the current place directly predicted recycling behavior, whereas the condition of recycling facility and personal recycling skill provided both a direct effect on the actual behavior and an indirect effect via recycling intention. In contrast, the psychological factors; attitude toward recycling, subjective norm, and awareness of recycling benefit, only indirectly influenced recycling behavior through the intention. The economic incentive, perceived efforts on time and space, and other demographic variables were not found significant in both levels.
\end{abstract}

Keywords: Thai, recycling, waste, logistic regression, theory of planed behavior.

\section{Introduction}

Solid waste generation in Thailand has increased extensively along with population growth, economic expansion, as well as changes in consumption patterns. The Pollution Control Department [1] reported that the amount of generated waste had risen from 30,640 tons per day in 1993 to 41,023 tons per 
day in 2008. The excessive solid waste generation without proper treatments caused environmental effluences and has become an emerging concern. Recycling has been broadly promoted as one of the waste management strategies to reduce materials that need to be disposed of as well as to utilize valuable waste. Still, the recycling participation rate is rather low. Only approximately $20 \%$ of over 15 million tons of annually generated waste is being recycled, whereas it is estimated that the potential recyclable waste in Thailand is as high as $40-60 \%$ [2].

To encourage people to co-operate in recycling programs, it is important to understand the factors that influence people's behavior toward recycling. Despite its necessity, research on understanding the mechanism of the recycling decision of households in Thailand is critically rare. In response to the need, this research aims to investigate the role of socio-demographic factors, psychological factors, economic factors, and situational factors in influencing recycling behavior of Thai people in an integrated perspective.

\section{Theoretical framework}

The theory of reasoned action (TRA) and theory of planed behavior (TPB) have been well comprehended as models that provide a framework to explain the determinants of behavior in a social and psychological perspective. The TRA suggests that behavior is a direct function of intention which is formed by attitude toward that behavior and subjective norm. When one has high intention, it is likely that he or she will perform the behavior [3]. The TPB is an extension of TRA, proposed by Ajzen et al. [4]. In addition to the attitude and subjective norm, TPB adds the concept of perceived behavioral control (PBC) which is developed from self-efficacy theory originated by Bandura $[5,6]$ into the model. The PBC not only influences intention but also directly influences behavior. The TRA and TPB have been extensively applied to predict recycling behavior on many occasions [7-13]. However, many researchers supported the fact that there are other variables besides the elements of TRA and TPB that predict environmental behaviour [7, 8, 12-20]. This study considered relevant factors in accordance with previous studies and employed the TPB as the critical framework of the research.

\section{Research design}

\subsection{Instrument development}

The data of this research were obtained from personal interviews based on a structured questionnaire, designed following previous literature [10-13, 15, 21]. Pre-tests were held two times prior to the main survey to examine the quality of the questionnaire items. Participants in the pre-tests were 80 Thai citizens who had dwelled in Bangkok for at least 90 days. In addition to the close-ended questionnaire, an open interview was also applied to acquire personal opinions. The internal consistency of question dimensions was measured by Conbach's 
alpha coefficient which indicates the degree to which a set of items measures a single unidimensional latent construct, values from 0 to 1 . Values above 0.7 indicate a good internal consistency [22]. The results of the second pre-test were satisfied in every question, with the alpha coefficients ranged from 0.71 to 0.88 . The verified questionnaire survey consisted with 3 parts; 1) questions regarding socio-demographic information, 2) questions regarding recycling behavior and intention, and 3) six-point scales question items on psychological, situational, and economic factors (strongly disagree $=1$ to strongly agree $=6$ ).

\subsection{Sampling and data collection}

Bangkok was selected for the study area. The target population was individuals who had been living in Bangkok for not less than 90 days. A multi-stage sampling method was applied to gather research samples. The information of a total of fifty districts in Bangkok was firstly examined. Inner-Bangkok, which is classified as a residential and business area [23], was selected as the interest group. Pathumwan district was randomly selected from 21 districts in the next stage by drawing lots. In the third stage, the number of samples required was calculated by using Krejcie and Morgan's formula [24].

$$
\mathrm{n}=\frac{\mathrm{X}^{2} \mathrm{NP}(1-\mathrm{P})}{\mathrm{d}^{2}(\mathrm{~N}-1)+\mathrm{X}^{2} \mathrm{P}(1-\mathrm{P})}
$$

where $n=$ required sample size, $X^{2}=$ table value of chi-square for 1 degree of freedom at the $95 \%$ confidence level (3.841), $N=$ population size, $P=$ population proportion (assumed to be 0.50 since this would provide the maximum sample size), and $d=$ degree of accuracy expressed as a proportion 0.05 or $5 \%$ margin error.

According to the population and housing statistics provided by the Department of Provincial Administration [25], Pathumwan district has a population of 58,858 people (male 27,463; female 31,395) as of 2009. Based on the sampling formula, 381 samples were required at a $5 \%$ margin of error. In the last stage, the number of samples required for each sub-district (Roungmuan, Wangmai, Pathumwan, Lumphinee) in Pathumwan ward was calculated by the ratio-sampling method.

\subsection{Analysis methodology}

Logistic regression analysis was employed to estimate the significant effects of explanatory variables in the study. The logistic regression works with odds which refer to the ratio of proportions for the two possible outcomes [26-28]. If the probability of $\mathrm{Y}=1$ is $\mathrm{P}$, then $1-\mathrm{P}$ is the probability when $\mathrm{Y}=0$. The odds can be written as eqn. (1).

$$
\text { Odds }=\frac{\mathrm{P}}{1-\mathrm{P}}=e^{\alpha+\beta_{1} X_{1}+\beta_{2} X_{2} \ldots \beta_{k} X_{k}}
$$

Hence, the odds, or the ratio of the probability of $\mathrm{Y}=1$ to its complement could be defined as eqn. (2).

$$
\mathrm{P}\left(\mathrm{Y}=1 \mid \mathrm{X}_{\mathrm{i}}\right)=\frac{e^{\alpha+\beta_{1} X_{1}+\beta_{2} X_{2} \ldots \beta_{k} X_{k}}}{\left(1+e^{\alpha+\beta_{1} X_{1}+\beta_{2} X_{2} \ldots \beta_{k} X_{k}}\right)}
$$


where $X$ refers to explanatory variables 1 to $\mathrm{k}$ and $i$ refers to samples 1 to $\mathrm{n}$.

Since the odds can take any positive values and so have no ceiling restriction, a logistic transformation is applied to remove the floor restriction. A multiple logistic regression model is abbreviated as eqn. (3)

$$
\operatorname{logit}\left(\mathrm{Y}=1 \mid \mathrm{X}_{\mathrm{i}}\right)=\log \left[\frac{\mathrm{P}(\mathrm{Y}=1)}{1-\mathrm{P}(\mathrm{Y}=1)}\right]=\alpha+\beta_{1} X_{1}+\beta_{2} X_{2} \ldots \beta_{k} X_{k}
$$

Parameters in logistic regression model are estimated by the maximum likelihood method [26]. The statistical significance of each coefficient is evaluated using the Wald test. The regression coefficient $\beta$ represents the change in the logit of the probability from a unit change in the associated predictor, holding other factors constant. The coefficients or the log-odds can also be interpreted after anti-log, by exponentiating, as the change in the ratio of probability of outcome $\mathrm{Y}=1$ over $\mathrm{Y}=0$ for a unit change in the associated explanatory factor, ceteris paribus [27-29]. The goodness-of-fit of the logistic regression models in this study was analyzed using a) the -2log-likelihood statistic, or the deviance, which measures unexplained variation in the model. The larger the value expresses the less accurate the predictions of the model; b) the Omnibus test which is a likelihood-ratio chi-square test whether the coefficients of the variables in the model are all jointly equal to zero; c) the Hosmer \& Lemeshow goodness of fit test which examines the null hypothesis that the model adjust well to the data; and d) the Nagelkerke $\mathrm{R}^{2}$ which reveals the amount of variation in the outcome variable that is explained by the model, having maximum value equal to 1 .

\section{Data analysis}

\subsection{Descriptive analysis}

The median age of the respondents was 28 years old. Most of the respondents were female $(56.7 \%)$, had completed undergraduate school $(63.3 \%)$, were single (70.9\%), living in a single house $(55.9 \%)$, and having a personal monthly income of 10,001 to 20,000 Thai baht $(41.7 \%)$. Of the total 381 samples, 217 respondents $(57 \%)$ reported that they involve themselves in recycling activities while 231 respondents $(60.6 \%)$ reported that they have intentions to recycle. The samples demonstrated appropriate representatives of Bangkok population of which $52.4 \%$ is female; the median age is a range of 20 to 34 years old, per capita income on average equal to 11,284 Baht [30]. However, the sample group was better educated than the populations which have the average years of educational attainment at 12 years [31].

\subsection{Principal component analysis}

Principal component analysis (PCA) was carried out prior to constructing the logistic regression model to examine the empirical dimensions of questionnaire data measured on ordinal scales [32,33]. To measure the competence of PCA to the initial variables, the Kaiser-Meyer-Olkin (KMO) statistic and the Bartlett's test was performed. The KMO measure of sampling adequacy provides an index 
ranges from 0 to 1 . A value close to 1 indicates that patterns of correlations are relatively compact and so factor analysis should yield distinct and reliable factors. The Bartlett's test evaluates whether the correlation matrix of initial variables is significantly different from the identity matrix. The PCA can be applied if the hypothesis that these matrixes are equal is rejected $[34,35]$. The results of the PCA performed with twenty-seven items on psychological, situational, and economic factors, obtained from the third part of the questionnaire survey, were summarized in table 1. No problematic collinearity across dimensions was found. The factor loadings demonstrated 10 dimensions. All components in aggregate explained $92.76 \%$ of the total variance in the data. $\mathrm{KMO}=0.73$ showed a modest sampling adequacy of factor analysis. The Bartlett's test is highly significant at p-value equal to 0.00 , approved that the PCA is applicable.

The seven non-scaled socio-demographic variables and ten scaled variables after performing PCA were double examined for multicollinearity problem by testing the Variance Inflation Factor (VIF) which measures the impact of collinearity among the independent variables in a regression model. As a rule of thumb, VIF of a variable above 10 indicates a multicollinearity problem [26]. The value of examined VIF ranged from 1.147 to 2.181 , confirmed that there was no multicollinearity problem among seventeen explanatory variables.

\subsection{Logistic regression analysis}

The capability of variables at each level to predict relevant variables at subsequent levels was examined by hierarchical logistic regression analyses. To test whether the factors present direct effects on recycling behavior or indirect effects via the intention, explanatory variables in the study were estimated in two stages; the first stage with recycling intention as the dependent variable, the second stage with recycling behavior as the dependent variable. Both intention to recycle and recycling behavior were measured by self-report binary scale.

To measure the predictors of intention to recycle in the first stage, a two-step hierarchical logistic regression analysis was applied. The socio-demographic variables which are classified as the factors at the lowest level were entered on the first step. The seven variables together provided a model that correctly classified $64 \%$ of the sample $(82.3 \%$ of sample with intention to recycle; $36 \%$ of sample with no intention to recycle). Hosmer and Lemeshow test was significant demonstrated that the model with only demographic variables did not adjust well to the data. Entering the ten variables on the next step amplified the percentage of respondents correctly classified to $90 \%(92.2 \%$ of sample with intention to recycle; $86.7 \%$ of sample with no intention). Hosmer and Lemeshow test become insignificant. Omnibus test of model coefficients was significant showed that inclusion of the second-step variables improved the model. Nagelkerke $\mathrm{R}^{2}$ improved from 0.116 to 0.738 . The value of -2 log-likelihood also decreased from 476.680 to 210.823 presented more accurate the predictions of the model. The attitude toward recycling, external subjective norm, awareness of recycling benefit, perceived facility condition, and perceived recycling skill were significant predictors of recycling intention, table 2 . 
Table 1: Results of the principal component analysis.

\begin{tabular}{|c|c|c|}
\hline Items & Loadings $^{\text {a }}$ & $\begin{array}{c}\% \text { of Variance } \\
\text { explained }\end{array}$ \\
\hline Component 1: Perceived space needed for recycling & & 21.33 \\
\hline I feel that recycling waste is space consuming & +0.947 & \\
\hline I feel that storing recycle waste affects using space in my house & +0.924 & \\
\hline I feel that recycling waste is inconvenience in term of space & +0.938 & \\
\hline Component 2: Perceived facility condition & & 17.66 \\
\hline I feel that it is easy for me to find recycling service & +0.915 & \\
\hline I agree that I am provided good recycling facility & +0.941 & \\
\hline I feel that recycling service is convenient to access. & +0.930 & \\
\hline Component 3: Economic incentive & & 9.56 \\
\hline Economic intensive is a factor persuading me to recycle waste & +0.927 & \\
\hline $\begin{array}{l}\text { I feel that economic returns from recycling waste make me want to } \\
\qquad \text { recycle }\end{array}$ & +0.957 & \\
\hline I agree that economic rewards affect my recycling behavior & +0.955 & \\
\hline Component 4: Adequacy of recycling information & & 9.09 \\
\hline I feel that am well provided information about recycling & +0.946 & \\
\hline I often find recycling information commonly & +0.903 & \\
\hline I agree that I am accessible to information regarding recycling & +0.937 & \\
\hline Component 5: Perceived recycling skill & & 8.32 \\
\hline I feel that I have ability to recycle waste properly & +0.906 & \\
\hline I agree that it is not troublesome for me to sort recyclable waste & +0.912 & \\
\hline I think that I know well the process of recycling household waste & +0.892 & \\
\hline Component 6: Perceived time needed for recycling & & 7.33 \\
\hline I feel that recycling waste is time consuming & +0.821 & \\
\hline I feel that it takes times to separating recyclable waste from others & +0.914 & \\
\hline I feel that recycling waste is inconvenience in term of time & +0.923 & \\
\hline Component 7: Attitude toward recycling & & 5.80 \\
\hline I feel that recycling waste is beneficial & +0.903 & \\
\hline I feel that recycling waste is valuable & +0.924 & \\
\hline I feel that recycling waste is good & +0.881 & \\
\hline Component 8: Internal subjective Norm & & 5.38 \\
\hline My household members see that recycling is good & +0.934 & \\
\hline People who are living with me supports recycling activities & +0.945 & \\
\hline Component 9: External subjective Norm & & 4.48 \\
\hline My friends or colleagues see that recycling is good & +0.934 & \\
\hline $\begin{array}{l}\text { People who are close to me but not living together support recycling } \\
\text { activities }\end{array}$ & +0.950 & \\
\hline Component 10: Awareness of recycling benefit on waste problem & & 3.82 \\
\hline I agree that recycling helps utilizing valuable waste & +0.955 & \\
\hline I agree that recycling is a solution for reducing waste problem & +0.948 & \\
\hline
\end{tabular}

${ }^{\mathrm{a}}$ After Varimax rotation with Kaiser Normalization. ${ }^{\mathrm{b}}$ Extraction Method: Principal Component Analysis. 
Table 2: Estimated regression coefficients of the logistic regression model predicting recycling intention.

\begin{tabular}{|c|c|c|c|c|}
\hline \multirow{2}{*}{ Predictors } & \multicolumn{2}{|c|}{ Step1 } & \multicolumn{2}{|c|}{ Step2 } \\
\hline & $\beta$ & $\operatorname{Exp}(\beta)$ & $\beta$ & $\operatorname{Exp}(\beta)$ \\
\hline Gender & -0.437 & 0.646 & 0.089 & 1.094 \\
\hline \multicolumn{5}{|l|}{ Single } \\
\hline Married & 0.129 & 1.137 & 1.214 & 3.366 \\
\hline Divorce & -1.080 & 0.340 & -0.839 & 0.432 \\
\hline House type & -0.272 & 0.762 & -0.831 & 0.436 \\
\hline \multicolumn{5}{|l|}{ Income less than 10000 Thai baht } \\
\hline Income 10001-20000 Thai baht & -0.324 & 0.723 & -0.899 & 0.407 \\
\hline Income 20001-30000 That baht & -0.401 & 0.669 & 0.122 & 1.130 \\
\hline Income 30001-40000 Thai baht & -1.104 & 0.332 & -0.552 & 0.576 \\
\hline Income 40001-50000 Thai baht & -0.417 & 0.659 & -1.560 & 0.210 \\
\hline Income more than 50000 Thai baht & -0.219 & 0.803 & 0.607 & 1.835 \\
\hline \multicolumn{5}{|l|}{ Junior high school or lower } \\
\hline High school & -0.863 & 0.422 & -1.531 & 0.216 \\
\hline Undergraduate & -0.700 & 0.497 & -1.825 & 0.161 \\
\hline Graduate or higher & -1.165 & 0.312 & -1.176 & 0.309 \\
\hline Age & 0.028 & 1.028 & -0.028 & 0.972 \\
\hline Resident year & $0.040 *$ & 1.041 & 0.013 & 1.014 \\
\hline Attitude toward recycling & & & $1.109^{* *}$ & 3.032 \\
\hline Internal subjective Norm & & & -0.117 & 0.889 \\
\hline External subjective Norm & & & $0.496^{*}$ & 1.642 \\
\hline Awareness of recycling benefit & & & $0.465^{*}$ & 1.592 \\
\hline Economic incentive & & & -0.151 & 0.860 \\
\hline Perceived space needed for recycling & & & -0.188 & 0.829 \\
\hline Perceived time needed for recycling & & & 0.141 & 1.151 \\
\hline Perceived facility condition & & & $1.777 * *$ & 5.910 \\
\hline Perceived recycling skill & & & $1.324 * *$ & 3.758 \\
\hline Adequacy of recycling information & & & 0.232 & 1.261 \\
\hline
\end{tabular}

Dependent variable $=$ Recycling intention $(1=$ have intention, $0=$ do not have intention)

$\operatorname{Exp}(\beta)=$ Exponentiated $\beta$

Statistically significant at the $* 0.05$ and $* * 0.01$ level.

In the second stage, a three-step hierarchical logistic regression analysis was employed to measure the predictors of recycling behavior. The recycling intention was entered into the model on the third step. The socio-demographic variables entered on the first step provided a model that correctly classified $63.3 \%$ of the sample (74.2\% of recycler; $48.8 \%$ of non-recycler). Hosmer and Lemeshow test was still significant. Entering psychological, situational, and economic variables on the second step increased the percentage of respondents correctly classified to $89 \%$ (90.3\% of recycler; $87.2 \%$ of non-recycler). Hosmer and Lemeshow test became insignificant. Omnibus test of model coefficients showed a significant contribution of the entered variables. Nagelkerke $\mathrm{R}^{2}$ increased from 0.141 to 0.731 . The $-2 \log$-likelihood decreased from 478.459 to 221.105. All goodness-of-fit indicators demonstrated a more accuracy of the model. The resident year, perceived facility condition, perceived personal 
Table 3: Estimated regression coefficients of the logistic regression model predicting recycling behavior.

\begin{tabular}{|c|c|c|c|c|c|c|}
\hline \multirow{2}{*}{ Predictors } & \multicolumn{2}{|c|}{ Step1 } & \multicolumn{2}{|c|}{ Step2 } & \multicolumn{2}{|c|}{ Step3 } \\
\hline & $\beta$ & $\operatorname{Exp}(\beta)$ & $\beta$ & $\operatorname{Exp}(\beta)$ & $\beta$ & $\operatorname{Exp}(\beta)$ \\
\hline Gender & -0.412 & 0.662 & 0.370 & 1.448 & 0.562 & 1.755 \\
\hline \multicolumn{7}{|l|}{ Single } \\
\hline Married & -0.034 & 0.966 & 1.076 & 2.932 & 0.313 & 1.367 \\
\hline Divorce & -1.054 & 0.349 & -0.662 & 0.516 & -0.230 & 0.794 \\
\hline House type & -0.302 & 0.739 & -0.293 & 0.746 & 0.027 & 1.027 \\
\hline \multicolumn{7}{|l|}{ Income less than } \\
\hline \multicolumn{7}{|l|}{10000 Thai baht } \\
\hline Income $10001-20000$ Thai baht & -0.115 & 0.891 & -0.266 & 0.766 & 0.819 & 2.268 \\
\hline Income 20001-30000 Thai baht & -0.222 & 0.801 & 0.762 & 2.142 & 1.461 & 4.312 \\
\hline Income $30001-40000$ Thai baht & -0.763 & 0.466 & 0.805 & 2.236 & 2.383 & 10.832 \\
\hline Income 40001-50000 Thai baht & -0.001 & 0.999 & -0.519 & 0.595 & 1.319 & 3.738 \\
\hline $\begin{array}{l}\text { Income more than } \\
50000 \text { Thai baht }\end{array}$ & 0.169 & 1.184 & 1.482 & 4.402 & 1.743 & 5.713 \\
\hline \multicolumn{7}{|l|}{ Junior high school or lower } \\
\hline High school & -0.370 & 0.690 & -1.316 & 0.268 & -1.272 & 0.280 \\
\hline Undergraduate & -0.373 & 0.689 & -1.808 & 0.164 & -2.177 & 0.113 \\
\hline Graduate or higher & -1.010 & 0.364 & -1.678 & 0.187 & -2.343 & 0.096 \\
\hline Age & 0.032 & 1.032 & -0.032 & 0.969 & -0.021 & 0.980 \\
\hline Resident year & $0.052 * *$ & 1.053 & $0.049^{*}$ & 1.051 & $0.070^{*}$ & 1.073 \\
\hline Attitude toward recycling & & & 0.309 & 1.362 & -0.728 & 0.483 \\
\hline Internal subjective norm & & & 0.333 & 1.395 & 0.504 & 1.656 \\
\hline External subjective norm & & & 0.328 & 1.388 & 0.110 & 1.117 \\
\hline Awareness of recycling benefit & & & 0.226 & 1.254 & -0.069 & 0.933 \\
\hline Economic incentive & & & -0.316 & 0.729 & -0.353 & 0.702 \\
\hline $\begin{array}{l}\text { Perceived space needed for } \\
\text { recycling }\end{array}$ & & & -0.020 & 0.980 & 0.370 & 1.448 \\
\hline $\begin{array}{l}\text { Perceived time needed for } \\
\text { recycling }\end{array}$ & & & 0.221 & 1.247 & 0.099 & 1.104 \\
\hline Perceived facility condition & & & $1.653^{* *}$ & 5.220 & $0.840^{* *}$ & 2.317 \\
\hline Perceived recycling skill & & & $1.491^{* *}$ & 4.441 & $1.302 *$ & 3.677 \\
\hline $\begin{array}{l}\text { Adequacy of recycling } \\
\text { information }\end{array}$ & & & $0.850^{*}$ & 2.339 & $1.391 *$ & 4.018 \\
\hline Intention to recycle & & & & & $5.486^{* *}$ & 241.280 \\
\hline
\end{tabular}

Dependent variable $=$ Recycling behavior $(1=$ recycle, $0=$ do not recycle $)$.

$\operatorname{Exp}(\beta)=$ Exponentiated $\beta$. Statistically significant at the $* 0.05$ and $* * 0.01$ level.

recycling skill, and perception of having adequacy recycling information significantly predicted recycling behavior in this level. The entry of the recycling intention variable on the last step improved the model substantially. The percentage of respondents correctly classified increased to $94.5 \%(96.3 \%$ of recycler; $92.1 \%$ of non-recycler). Hosmer and Lemeshow test was not significant. Omnibus test of model coefficients at 'step' and 'model' level were both significant. Nagelkerke $\mathrm{R}^{2}$ improved to 0.878 . The value of $-2 \log$-likelihood decreased to 116.357 . The resident year, perceived facility condition, perceived personal recycling skill, perception of having adequacy of recycling information, and recycling intention significantly predicted recycling behavior. 


\section{Conclusions and discussions}

This research aimed to acquire insights into household waste recycling behavior in Thailand by gaining an understanding of what factors influence households' decision to participate in recycling programs. The results demonstrated that the resident year and perceived adequacy of recycling information were direct predictors of recycling behavior, whereas the perceived facility condition and perceived recycling skill both directly influenced recycling behavior and indirectly influenced the behavior via intention. In contrast, the psychological factors; attitude toward recycling, external subjective norm, and awareness of recycling benefit, only provided indirect effect on recycling behavior. The results on subjective norm intensely suggested that recycling intention of people were likely to be influenced by norm of the involving societies than internal norm of household's members. The economic incentive, perceived efforts on time and space, and socio-demographic factors besides resident year were neither direct nor indirect predictors of recycling behavior. The reason why time and space were not significant predictors might be because the recycling programs were not advance to the rate that high effort on time and storing space become matters.

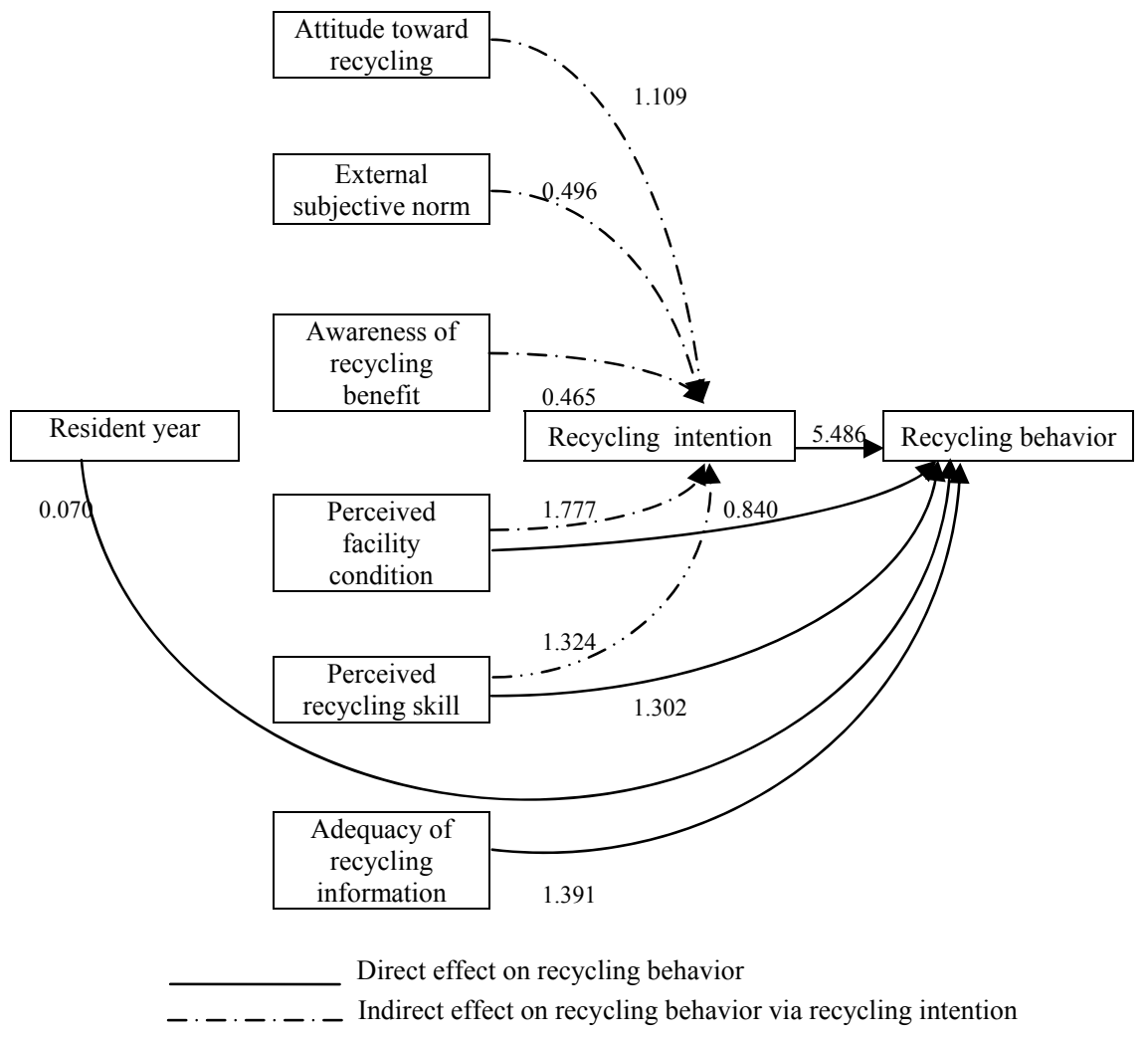

Figure 1: Path diagram of direct and indirect predictors of recycling behavior. 
The outcomes of the study suggest some directions for improving recycling participation. First, recycling facilities, services and other support systems should be expressly concerned. An insufficiency and inferiority of the system could largely demotivate willingness to recycle as well as hinder actual recycling behavior. Extensive attentions should be paid on the service accessibility and standard of disposal containers. The facility and service should be comfortable to get access. A universal standard of classification of separation container as well as sorting criteria should be clearly specified. Moreover, the actual installed facility must be steadied with information provided to people; otherwise it would cause further confusion and raise more perceived complexity of the recycling system. The significant impact of resident year, which in part reflected degrees of expertise in the facilities and services in the community, supported that a better understanding in the recycling system tended to positively affect recycling involvement of people.

In addition, perceived lack of recycling skills could be a significant barrier to recycling participation. Hence, people should be well educated how to recycle waste in practice; what materials should be separated, how to sort, and where to deposit them. The support systems and perceived recycling skills are crucial because these factors appeared to be the key factors of people's decision to drive their recycling intention to the actual action.

Policies on reinforcing positive attitude toward recycling and raising awareness of recycling benefits should also be concerned. Though the results revealed that the factors did not provided significant direct impact on recycling behavior, these two factors significantly influenced the intention to recycle which further manipulated the recycling participation.

Besides, people's recycling intention tended to depend significantly on recycling norm of their engaging communities. Whereas people were likely to intend to recycle when their involving societies have positive norm on recycling, people might also be hesitate to participate in recycling activities if they feel that recycling is an irregular practice in their participating societies. Therefore, it is important to make recycling an activist and favorable practice performed by a majority of people.

This study also has some limitations that should be refined. First, the behavior concerned in this study was self-reported. The respondents might be self-aware or have bias on reporting their recycling behavior. Other methods such as a diary report might be combined to overcome this limitation in the future study. Second, the survey covered only one geographical area. Future research might extend study areas and additionally investigate the different recycling behaviors of population with diverse characteristics and life styles, such as urban-rural citizens, to provide the best suit policy for different groups of people.

\section{References}

[1] Pollution Control Department (PCD), Ministry of Natural Resources and Environment. Thailand State of Pollution Report 2008. Rungsilp printing: Bangkok, 2010. 
[2] Shapkota, P., Coowanitwong, N., Visvanathan, C. \& Trankler, J., Potentials of recycling municipal solid waste in Asia vis-a-vis Recycling in Thailand. SEA-UEMA Project, pp. 195-220, 2006.

[3] Fishbein, M. \& Ajzen, I., Belief, attitude, intention, and behavior: An introduction to theory and research. Reading, Addison-Wesley: Boston, 1975.

[4] Ajzen, I., From intentions to actions: A theory of planned behavior. In Kuhl, J. \& Beckmann J., (eds). Action control: From cognition to behavior, Springer-Verlag: New York, 1985.

[5] Bandura. A., Self-Efficacy Mechanism in Human Agency. American Psychologist, 37 (2), pp. 122-147, 1982.

[6] Bandura. A., Self-Efficacy: Toward a Unifying Theory of Behavioral Change. Psychological Review, 84 (2), pp. 191-215, 1977.

[7] Cheung, S., Chan, D. \& Wong, Z., Reexamining the theory of planned behavior in understanding wastepaper recycling. Environment and Behavior, 31(5), pp. 587-612, 1999.

[8] Chu, P.-Y. \& Chiu, J.-F., Factors influencing household waste recycling behavior: Test of an integrated model. Journal of Applied Social Psychology, 33(3), pp. 604-626., 2003.

[9] Goldenhar, L.M. \& Connell, C.M., Understanding and predicting recycling behavior: an application of the theory of reasoned action. Journal of Environmental Systems, 22(1), pp. 91-103, 1993.

[10] Taylor, S. \& Todd, P., An integrated model of waste management behavior: A test of household recycling and composting intentions. Environment and Behavior, 27 (5), pp. 603-630, 1995.

[11] Taylor, S. \& Todd, P., Understanding Household Garbage Reduction Behavior: A Test of an Integrated Model. Journal of Public Policy \& Marketing, 14 (2), pp.192-204, 1995.

[12] Tonglet, M., Phillips, P.S. \& Read, A.D., Using the theory of planned behavior to investigate the determinants of recycling behavior: A case study from Brixworth, UK. Resources, Conservation and Recycling, 41(3), pp.191-214, 2004.

[13] Tonglet, M., Phillips, P.S. \& Bates, M.P., Determining the drivers for householder pro environmental behavior: waste minimization compared to recycling. Resources, Conservation and Recycling, 42(1), pp. 27-48, 2004

[14] Barr, S., Household Waste in Social Perspective: Values, Attitudes, Situation and Behavior. Aldershot publisher: Ashgate, 2002.

[15] Boldero, J., The prediction of household recycling of newspapers: The role of attitudes, intentions, and situational factors. Journal of Applied Social Psychology, 25(5), pp. 440-462, 1995.

[16] Hungerford, H.R. \& Volk, T., Changing learner behavior through environmental education. Journal of Environmental Education. 21(3), pp. 8-21, 1990.

[17] Gamba, R. \& Oskamp, S., Factors influencing community residents' participation in commingled curbside recycling programs. Environment and Behavior, 26(5), pp. 587-612, 1994. 
[18] Sia, A., Hungerford, H.R. \& Tomera, A.N., Selected predictors of responsible environmental behavior: An analysis. Journal of Environmental Education, 17(2), pp. 31-40, 1986.

[19] Vicente, P. \& Reis, E., Factors influencing households' participation in recycling. Waste Management \& Research, 26(2), pp. 140-146, 2008.

[20] Vining, J. \& Ebreo, A., What makes a recycler? A comparison of recyclers and nonrecyclers. Environment and Behavior, 22 (1), pp. 55-73, 1990.

[21] Valle, P., Reis, E., Menezes, J. \& Rebelo E., Behavioral Determinants of Household Recycling Participation: The Portuguese case, Environment and Behavior, 36(4), pp. 505-540, 2004.

[22] Cronbach, L., Coefficient alpha and the internal structure of tests. Psychometrika, 16(3), pp. 297-334, 1951.

[23] BMA data center, Bangkok Metropolitan Administration, Thailand. http://203.155.220.118/info/Default.asp

[24] Krejcie, R.V. \& Morgan, D.W., Determining sample size for research activities. Educational and Psychological Measurement, 30(3), pp.607-610, 1970.

[25] Department of Provincial Administration, Ministry of Interior, Thailand. The 2009 population and housing census, http://www.dopa.go.th

[26] Gujrati D.N., Basic econometrics. McGraw-Hill Book Company: New York, 2003.

[27] Hosmer, D. \& Lemeshow, S., Applied Logistic Regression. John Wiley and Sons: New York, 2000.

[28] Long, J., Regression models for categorical and limited dependent variables. Sage: London, 1997

[29] Flom, P.L. \& Strauss, S.M., Some graphical methods for interpreting interactions in logistic and OLS regression. Multiple Linear Regression Viewpoints, 29 (1), pp.1-7, 2003.

[30] National Statistical Office and Office of the National Economic and Social Development Board, Office of the Prime Minister, Thailand. Core Economic Indicators of Thailand 2008 online, http://service.nso.go.th/nso/nsopublish/indicator/indEco51.pdf

[31] Office of Education Council, Ministry of Education, Thailand. Average Years of Educational Attainment of Thai Population 2009 online, http://www.onec.go.th/onec_administrator/uploads/Book/991-file.pdf

[32] Jolliffe, I.T., Principal Component Analysis, 2nd edition, Springer-Verlag: New York, 2002.

[33] Shlens, J.,A tutorial on Principal Component Analysis, Princeton University, http://www.cs.princeton.edu/picasso/mats/ PCA-Tutorial-Intuition_jp.pdf

[34] Field, A., 2nd edition, Discovering statistics using SPSS. Sage Publications: Thousand Oaks, 2005.

[35] Kaiser, H., An index of factorial simplicity. Psychometrika, 39(1), pp.31-36, 1974. 